\title{
MomentDergi
}

Hacettepe Üniversitesi İletişim Fakültesi Kültürel Çalışmalar Dergisi

2019, 6(1): 260-266

ISSN: 2148-970X.

Kitap Eleştirisi

\section{OTORITERIZMIN YÜZLERI: POPÜLIZM VE FAŞIZM}

\section{Burak Gökalp*}

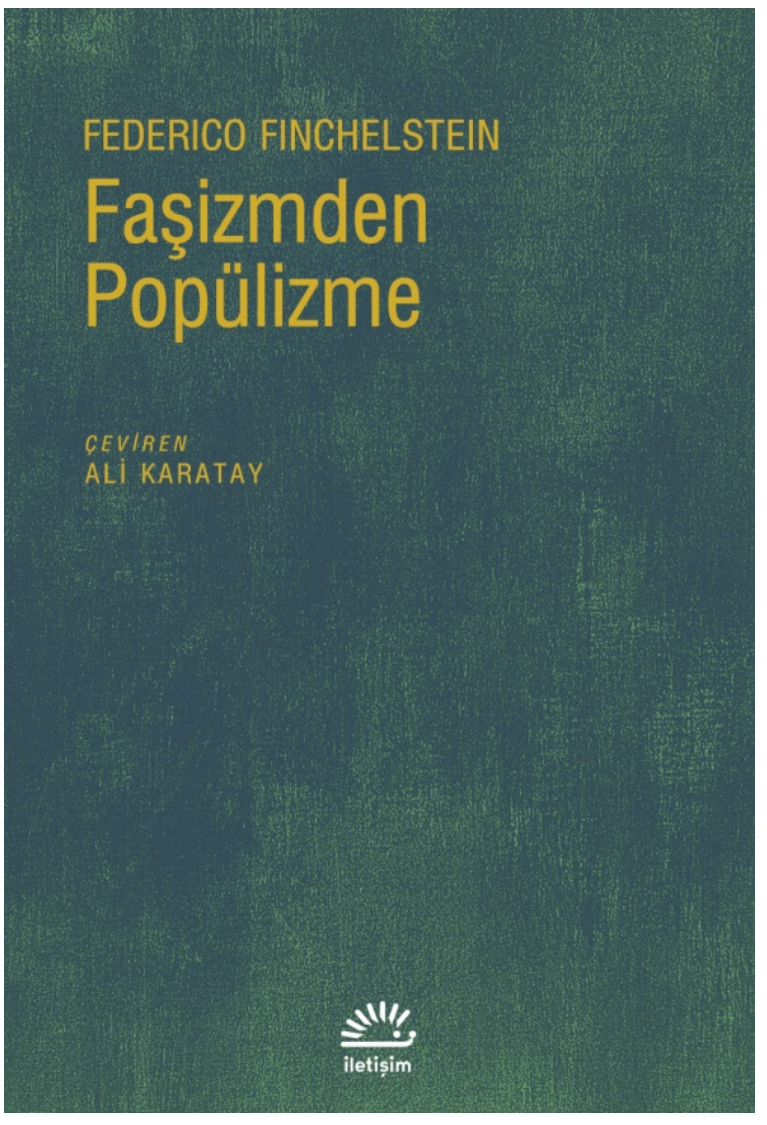

Finchelstein, F. (2019). Faşizmden Popülizme.

(A. Karatay, Çev.) İstanbul: İletişim. 320

Sayfa, ISBN: 9789750525926

Brown University, New School for Social Research ve Eugene College gibi okullarda faşizm ve popülizm dersleri veren Federico Finchelstein'1n "From Facism to Populism in History" başlıklı kitabı 2017 yılında University of California Press'den çıkmış ve okuyucuların beğenisine sunulmuştur. Yazarın çalışması, İspanyolca ve İtalyancaya çevrilmiş, ardından 2019 yılında İletişim Yayınları tarafından “Faşizmden Popülizme" ismi ile Türkçeye kazandırılmıştır.

Tarih alanında çalışmalarını yürüten Arjantinli yazar, bu kitapta faşizmi ve popülizmi sadece tarih disiplini çerçevesinde

* Doktora Öğrencisi, Pamukkale Üniversitesi, Siyaset Bilimi ve Kamu Yönetimi Bölümü ORCID ID: https://orcid.org/0000-0002-0652-5903 burak.gklp@gmail.com Yazının Geliş Tarihi: 31/05/2019 Yazının Kabul Tarihi: 10/06/2019

(C) Yazar(lar) (veya ilgili kurum(lar)) 2019. Atıf lisansı (CC BY-NC 3.0) çerçevesinde yeniden kullanılabilir. Ticari kullanımlara izin verilmez. Ayrıntılı bilgi için açı erişim politikasına bakınız. Hacettepe Üniversitesi İletişim Fakültesi tarafından yayınlanmıştır. 
değil, tarihle beraber faşizmin teorisini de analize dâhil ederek teori-pratik dikotomisini aşmaya çalışmaktadır (Finchelstein, 2019, s. 52). Ona göre faşizm ve popülizm incelenirken "ideal tiplerden" ve Avrupa merkezli bakış açısından azade bir analiz yöntemi belirlenmeli ve "transatlantik" faşizm ve popülizmin gerçek yüzü ortaya çıkarılmalıdır. Zira ne faşizm ne de popülizm kötülügün vücut bulduğu tarihsel formlardır. Onlar "kendinde bir öz" olarak incelenmediği takdirde kendilerine has özellik ve tarihleri saklı kalacaktır.

Dünya tarihi boyunca devletler ve liderler kendi meşruiyetlerini sağlamak ve toplumu yönetmek amacıyla çeşitli politika biçimlerini benimsemişler ve kimi zaman bu politikaları devletin temel politikalarından biri haline getirmişlerdir. Modern öncesi dönemde meşruiyetin "nomos" $\mathrm{u}$ din iken aydınlanma dönemi sonrasında meşruiyetin temeli akıla dayanmaktadır. Akla dayanan yeni "modern" dönem ise politik dünyada meşruiyet biçimlerini milliyetçi toplumsal tahayyüller üzerinden sağlayarak, ulusal devlet formlarını siyasi olduğu kadar toplumsal olarak da onaylamaktadır.

Öncelikle, yazara göre, "modern bir siyasi hareket olarak faşizmin doğum yeri Kuzey İtalya, doğum tarihi 1919, babası ise Benito Mussolini'dir" (s. 59). Bu düşünce, farklı ülkelerde farklı isimlerle benimsenmiştir. Ancak faşizmin temsil ettiği temel değerler, aşağı-yukarı aynı kalmıştır. Bunlar; "anti-demokratik tutum”, "şiddete dayalı ve ırkçı sağ devrim" (s. 43), "aşırı milliyetçilik", "anti-liberalizm", "anti-marksizm", (s.40), "eril toplum yapısı" (s.70), "mitsel ve mistik anlatılar" (s. 66), "yarı-tanrı bir lider" (s. 252), "dost-düşman ayrımının radikalleşmesi" (s.69-70), "devlet fetişizmi" (s.73), "anti-çoğulculuk" (s.75) ve "geçmişteki altın çağa/imparatorluğa dönüş arzusu"dur (s. 119). Bu bağlamda faşist ideoloji Gellner'in (2008, s. 56) ifadesi ile bir "kendine tapma" biçimidir. Gellner, Durkheim'ın dinler üzerine Feuerbuchvari getirdiği yorumu hatırlatır. Dinler, toplumun kendi imajına gizliden tapmasıdır. Ancak, artık insan kendine açık açık tapmaktadır ve adına "milliyetçilik" demektedir. Radikal bir milliyetçilik ve ırkçllık biçimi olan faşizimde ise toplum kendisine, kendisini özdeştirdiği devlete ve lidere tapınmaktadır. Bu mistik teslis, faşizmin kurucu temelidir

Faşizm, yeni bir siyasal düzen yaratması bakımından devrimci bir ideolojidir (s. 74). Eski düzen yıkıldığında ve faşizm iktidara geldiğinde yukarıda zikredilmiş olan üçlü yapı kurulur. Bu yapının bir ayağını lider oluştururken, diğerlerini halk ve devlet oluşturur (s. 114). Halkların (demos) yükselişe geçtiği 20. yy'da alternatif bir modernite inşa eden faşizm, seküler-politik bir din yaratmıştır (s. 114). Hayes'in (2010, s. 189) milliyetçiliği bir din olarak tanımladığı anımsandığında, faşizmin dinsel doğasının "radikal milliyetçilik" bağlamında "radikal bir politik din" olduğu yargısına ulaşılabilir. 
Faşizmin devinimini sağlayan temel itici güç ise şiddettir. Şiddet, bir araçtan ziyade bir amaçtır. Bu ideolojide şiddet kutsal bir "kolektif iletişim biçimi" olarak ortaya çıar. Yazar, şiddetin varoluşsal düşmana yöneldiğinin altını çizer (s. 112). Faşistlere göre faşist olmayan herkes mutlaka lider ve halkın oluşturduğu ulusal topluluğun karşısında olan zehirlenmiş insanlardır. Faşist siyasette onların meşru bir yeri yoktur (s. 113). Aslında faşistler için kurgu basittir. Onlara göre iktidar şiddettir, bu vesileyle iktidar pratikleri şiddet biçimlerinde görünmektedir. Onaylama-dışlama pratikleri katı kurallarla belirlenmiş olan faşizm, iktidarın şiddetini; lider, ulus devlet ve halktan oluşan modern siyasi mit üzerinden meşrulaştırır.

Marksizm ve liberalizm gibi faşizm de birçok ulusal varyasyon ve siyasi yorumlama biçimi olan küresel bir fenomendir. Ancak, diğer ideolojilere kıyasla faşizmin hayatı daha kısa sürmüştür. II. Dünya Savaşı'nın ardından -özellikle Almanya'nın ağır yenilgisi ile- faşizmin politik geçerliliğini kaybetmesi ve "demokratik" Batı ile "diktatöryal" Doğu arasında bölünen iki kutuplu dünyanın, 1989'da Sovyet Sosyalist Cumhuriyetler Birliği'nin (SSCB) dağılmasıyla beraber ortadan kalkmasıyla, dünya yeni bir "gelecek" ile karşı karşıya kalmıştır. Fukuyama'nın (1989, s. 3) ifadesi ile SSCB'nin dağılmasıyla sona eren sadece Soğuk Savaş değildir. Tarihin kendi de sona ermiş ve dünya artık Liberal Demokrasi ile entelektüel ve politik evrimini tamamlamıştır. Ancak gerçekten öyle midir? Demokrasinin kesin (!) zaferine rağmen Latin Amerika'dan Avrupa ile Asya'ya yayılan ve son yıllarda da ABD'de giderek artan "otoriterleşme" eğilimi, açıkca demokrasiyle çelişirken, faşizan eğilimlerin, nefret dilinin ve ırkçılığın gittikçe güçlenmesi, Fukuyamacı anlayışa ters düşecek bir gerçekliğin ipuçlarını vermektedir.

Yazar, demokrasi içerisindeki söz konusu otoriter eğilimler için popülizmi işaret etmektedir. Modern popülizm; II. Dünya Savaşı sonrası faşizmin yeniden formülasyonundan doğmuş otoriter bir demokrasi biçimidir (s. 32-141). Bu siyaset biçiminin ilk uygulandığı yer Arjantin, ilk uygulayıcısı ise General Peron'dur. Peronizmi diğer popülizm biçimlerinden ayıran en temel özellik ise onun kendi tarihi boyunca tüm olası popülizm biçimlerini benimsemiş olmasıdır (s. 145). Popülistler, kendini önceleyen faşizm gibi ancak başka araçlar kullanarak halk adına karar alıp hareket etmişlerdir (s. 142). Faşizm nasıl hem "parlamenter demokrasi" modeline hem de SSCB'nin sosyalist projesine bir yanıtsa, popülizm de bunlarla beraber faşizme ve onunla beraber faşizmi yaratan, sonra onu yok eden temsil krizine bir yanıttır. Bu bağlamda faşizm; demokrasiyi, hukukun üstünlüğünü ve güçler ayrılığını alaşağı ederken, popülizm; bu kavramların altını yavaş yavaş oymayı tercih etmiştir (s. 142). 
Yazar, popülizmin 1945 yılı itibariyle geçirdiği evreleri ise dört başlık altında incelemektedir. Bunlar; klasik popülizm, Neoliberal Popülizm, Neoklasik sol popülizm, sağ ve aşırı sağ Neoklasik popülizmdir. Finchelstein klasik popülizme; Arjantin'den Peron'u, neoliberal popülizme Arjantin'den Carlos Menem'i, neoklasik sol popülizme yine Arjantin'den Krichner'ı ve sağ ve aşırı sağ Neoklasik popülizme ise Türkiye'den Recep Tayyip Erdoğan ile Macaristan'dan Obran'1 örnek olarak gösterir (s.145).

Finchelstein; popülist iktidar biçimlerinin ortak özelliklerini ise şu şekilde belirtir: Diktatörlügün reddi, siyasetin dinselleştirilmesi, kıyamet benzeri bir çöküş propagandası, mesihvari karizmatik lider, zayıf bir hukukun üstünlüğü ve zayıf bir güçler ayrılı̆̆ı anlayışı, radikal milliyetçililk, liderin halkı şahsında temsil etmesi, hareket ve lideri tümüyle halkla özdeşleştirme, anti-politiklik iddiası, halk adına konuşma, antielitizim, kendini diktatörlük karşıtı ve demokrasi savunucusu olarak pazarlama, homojen halk anlayışı, bağımsız gazetecilkten hazetmeme, çoğulculuk ve siyasi hoşgörü karşıtllı̆g (s. 146).

Bunlarla beraber, popülizm, iktidara geldiği yerlerde sosyal hakları genişletmekteyken, siyasal hakları kısıtlama eğilimi göstermektedir (s. 155). Bu durum onun toplumsal kutuplaşmayı destekleyici politikalarıla (s. 178) paralellik arz etmektedir. Diğer bir ifade ile popülizm elitler tarafından sömürülen ve ekonomik pastadan en küçük dilimi alan gerçek (!) "halkın" savunuculuğu pozisyonunda kendini konumlandırır. İktidara geldiğinde ise sosyal haklarda genişleme yaratarak tabanının gözünde meşruiyet kazanır. Bu taban artık "gerçek halk" tır ve geri kalanlar politik alanda meşru bir varlık gösteremezler. Yani popülizm, "hainler" yaratır ve bu "hainler"e yönelen politikalar bağlamında Schmitt'ci bir "siyasal olan" inşa eder.

Faşizm ile popülizmin arasındaki fark burada belirgin hale gelir. İlk olarak faşizm ötekiyi kurbanlaştırır. Toplama kamplarına toplar, işkence eder, öldürür. Yani şiddet; yüksek yoğunlukta ve fiili olarak uygulanmaktadır (s. 105-106). Bu bağlamda yazar, popülizmin şiddeti reddetiği önermesi ile iki kavramı ayırmaya teşebbüs eder. Ona göre popülizm şiddeti reddetmiş, böylece faşizime en büyük çekinceyi koymuştur (s. 32-45).

Yazar, kitabında faşizimde şiddetin merkeziliğinin yanında, popülizmde şiddetin retorikte kaldığını öne sürer (s. 31). Ancak burada yazarın şiddet anlayışının salt "fiziksel" olduğunun altını çizmek gerekir. Tarihsel olaylar ve bu alan üzerine oluşan literatür, yazarın şiddet bağlamında bu sınıflandırmasını desteklemektedir. Ancak burada yazarın "retorik" şeklinde ifade ettiği dilsel şiddet biçimlerinin şiddet kavramından dışlandığı görülür. Popülist iktidarlarda fiziksel şiddet, soykırım vb. suçlar yadsınırken şiddetin dilsel biçimleri övülür, parlatılır ve lider-devlet-halk teslisi için bir 
çimento vazifesi görür. Bu bağlamda, yazarın şiddete söz konusu yaklaşımı doğru ancak eksiktir. Özellikle ötekiye yönelen hakaret, aşağılama, ötekileştirici dilsel pratikler ve nefret söyleminin varlığı, faşizimde fiziksel olan şiddetin popülizmde yerini dilsel şiddete bıraktığını göstermektedir.

Finchelstein, popülizm ve faşizmi birbirinin devamı olarak görmez. Yani Faşizm popülizmin ön koşulu değildir (s. 45). Yazar, bu iddiasını temellendirmek adına, yani popülizmi basit bir şekilde faşizmin bir varyasyonu olarak okumamak için, faşizmin ve popülizmin ana akım ele alınış biçimlerine alternatif bir yol haritası ihtiyacını vurgulamaktadır. Popülizme ve özellikle Faşizme dair yapılan kimi çalışmaları ele alan yazar, bu kavramlara dair tarih yazımının toptancı okumasına karşı gelmektedir. Nazizm örneği bu konuda oldukça net bir örneği teşkil ederken yazar; faşizmin Avrupa tecrübesi örneğine indirgendiği iddiasını ileri sürer (s. 87). Alman Nazizmi, Arjantin'in Nacionelismo'su, Brezilya'nın Interoralismo'su İtalyan faşizmi ile aynı temel değerleri paylaşmak noktasında birleşirken, diğer taraftan kendi kültürel, politik, sosyal kodlarını da içeren yani kendi bağlamında oluşturulan faşizmler olarak onlardan ayrılmaktadır.

Faşizmin ideal bir tipi yoktur; dünyanın başka yerlerinde başka toplumsal ve tarihsel bağlamlarda ortaya çıkmış farklı dönemlerde farklı özellikler göstermiştir. Böyle bir genelleyici konsensüsün varlığı; faşizmin içinde bulunduğu karmaşık yapının analizinin sağlıklı yapılamaması sonucunu doğurur. Diğer bir ifade ile faşizmin bir Plâtoncu ideal tipinin varlı̆̆ına dair inanç sebebiyle, Avrupa dişında oluşan faşizmlerin "eylem gücü düşük" islamofaşist rejimler, ya da "caudillo" gibi farklı faşizm modelleri ortaya konulmuştur.

Liberalizm veya Marksizm gibi ideolojilerin ulus-aşırı incelendiği bir akademik dünyada faşizmin Avrupa merkezli bir düşünce biçimiyle ele alınması ise milliyetçilikle ilgilidir. Araştırmacılar, faşizm ile kirlenmiş bir tarih yazmak istemedikleri için bunlara farklı isimler vermek ve farklı sınıflandırmalar altında toplamak istemektedirler (s. 9192).

Bu yaklaşımın aksine ulus-aşırı yaklaşıma göre tarih; yalnızca aktarımların değil, aynı zamanda aktarılmamış ya da özgül ulusal geçmişleri nedeniyle dışarıya başarıyla aktarılması mümkün olmamış unsurların bir tarihidir. Bu tutum; ideal tiplerden ve "asgari" şartların belirlediği bir tarih anlayışından uzaktır. Bu bağlamda Liberalizm veya Marksizm en nihayetinde bir ulusal bağlamdan diğerine farklılık gösteren bir ideolojidir (s. 93-94). Örneğin Arjantin'de faşist yönetim koyu bir Katoliklikle harmanlanmış ve dinsel-faşist bir yönetim kurulmuştur. Diğer taraftan Japonya'da faşist yönetim; geçmişin restorasyonu nosyonu ile meşruiyet kazanmış, "o altın dönemi yeniden getirme" 
düşüncesi üzerine örgütlenmiştir (s. 93). Burada yazarın kendine postmodern bir pozisyon benimsediği görülmektedir. Yani özcü bir pozisyonu benimsemek, aksiyomlarla hareket etmek yerine her bir faşizm tecrübesini kendi özünde anlamlı bir bağlamı olduğu düşüncesiyle tarihsel analize konumlandırmaktadır. İşte tam bu noktada, teori ve pratik arasındaki dikotomiyi aşmak mümkün olmaktadır. Yazar bu vesile ile faşizm hakkında aydınlanmamış alanlara, hem teorik hem de pratik olarak ışık tutmuştur.

Finchelstein'ın bir tarihçi olarak faşizmi ve popülizmi ulus aşırı inceleyen çalışması, tarihsel şahsiyetlerden anekdotlarla ve tarihsel olaylarla zenginleştirilmiştir. Ancak, tarih alanında yakaladığını iddia ettiği anti-indirgemeci tutumun tek yanlı olması bu zenginliğin de tek yanlı çalışmasına sebep olmuştur. Zira faşizmin veya popülizmin tarihi ele alınıyorsa da, bu sadece onun tarihinden ibaret yazılamaz. Çünkü bir iktidar ilişkisini imleyen bu kavramlar iktidarın öznesi ve nesnesi arasındaki ilişkisinin temsilidir. Diğer bir ifade ile faşizm veya popülizm denildiğinde iktidarı sadece uygulayan değil, o iktidara muhatap olan da anlaşılmalıdır. Bu sebepten dolayı, belki de kitabın en zayıf noktası, iktidarın muhataplarına yer vermemesidir. Örneğin "faşist iktidarları halk neden kabul edip meşru saymıştır?" veya "popülist iktidarlarda ben-öteki ilişkisinin hainler ve vatanseverler şeklinde kurulmasını halk neden benimsemiştir?" gibi sorulara cevap vermez. Diğer bir ifade ile Annales ekolünün aksine, yazar büyük anlatılara yoğunlaşmış ve faşizmi sadece uygulayıcıya indirgeyip halkı edilgen bir politik değişken olarak ele almıştır.

Tam da bu noktada bir diğer eleştirinin kapısı açılmaktadır. Zira kitabın orijinal baskısında da Türkçe tercümesinde de örneğin lider, devlet ve halk bütünleşmesinden bahsedilirken "Public" (Halk) ifadesi kullanılır. Ancak bu ifade renksiz ve gömleksiz bir topluluğun ifadesidir. Yani faşist veya popülist iktidar biçimlerinde halk sadece devlet içinde yaşayan insanlar değildir. Aksine onların belirgin bir rengi vardır ki bu radikal milliyetçi söylemde kendini bulur. Kojin Karatani'nin ifadesiyle modern ulus devletler özünde kapital-ulus-devletlerdir (Karatani, 2008, s. 585-586). Yani devletin iktidarını konu alan bir çalışma, kapitalist örgütlenme ve millet formasyonuyla ilişki kurmadan yürütüldüğünde, söz konusu iktidar biçimini oluşturan, işleten ve meşrulaştıran maddi gerçekliğin anlaşılması güçleşmektedir. Bu bağlamda yazar, faşizme özgü korporatist biçim ve popülizmin neoliberalizm ile ilişkisi bağlamında anlizlere kısa da olsa değinir.

Özetle, yazarın faşizmi ve popülizmi ele aldığı bu kitabı söz konusu iki iktidar formunun da hakkıyla incelenmesi için daha karmaşık ve daha çok derinlemesine analizi gerekli kılan bir yol önermektedir. Diğer taraftan, oryantalizmden azade söz konusu 
tutumun, Türkiye özelinde popülizm ve faşizm incelemelerinde faydalı, bir o kadar da tartışma yaratıcı sonuçlara gebe olduğunu belirtmek gerek. Bir başka ifade ile faşizmi ve popülizmi bir ideal tipe bağlı kalmadan tartışmanın bir sonucu olarak, ileride literatürde “Türk tipi faşizm" veya "Türk popülizmi" tarzı ifadelerin yer bulacağı bir zemin oluşmaktadır.

\section{Kaynaklar}

Finchelstein, F. (2019). Faşizmden Popülizme. (A. Karatay, Çev.) İstanbul: İletişim. Fukuyama, F. (1989). The End of History? The National Interest , 3-18.

Gellner, E. (2008). Nations and Nationalisms. New York: Cornell University Press. Hayes, C. (2010). Milliyetçilik: Bir Din (2. Baskı b.). (M. Çiftkaya, Çev.) İstanbul: İz. Karatani, K. (2008). Beyond Capital-Nation-State. Rethinking Marxism , 569-595. 